\title{
Ophthalmologica
}

Ophthalmologica 2017;238:205-216

DOI: $10.1159 / 000478665$
Received: November 23, 2016

Accepted after revision: June 12, 2017

Published online: September 2, 2017

\section{SAVE-AMD: Safety of VEGF Inhibitors in Age-Related Macular Degeneration}

\author{
Frank Enseleit $^{\mathrm{b}}$ Stephan Michels ${ }^{\mathrm{a}}$ Isabella Sudano ${ }^{\mathrm{b}}$ Marc Stahel $^{\mathrm{a}}$ \\ Sandrine Zweifel ${ }^{c}$ Oliver Schlager ${ }^{b}$ Matthias Becker ${ }^{a}$ Stephan Winnik ${ }^{b}$ \\ Matthias Nägele $^{b} \quad$ Andreas J. Flammer ${ }^{b} \quad$ Michel Neidhart $^{d} \quad$ Nicole Graf $^{f}$ \\ Christian M. Matter $^{\mathrm{b}}$ Burkhardt Seifert ${ }^{\mathrm{e}}$ Thomas F. Lüscher $^{\mathrm{b}}$ \\ Frank Ruschitzka ${ }^{b}$ \\ ${ }^{a}$ Department of Ophthalmology, City Hospital Triemli Zurich, ${ }^{b}$ Department of Cardiology, \\ University Heart Center, 'Department of Ophthalmology, and ${ }^{\mathrm{d} C l i n i c}$ for Rheumatology, University Hospital Zurich,

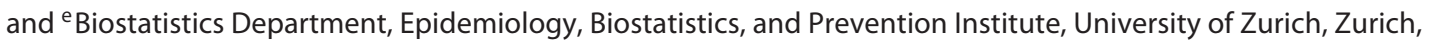 \\ and ${ }^{\mathrm{f}} \mathrm{Graf}$ Biostatistics, Winterthur, Switzerland
}

\section{Keywords}

Age-related macular degeneration - Endothelial function . Vascular endothelial growth factor - Clinical trial .

Ranibizumab · Bevacizumab

\begin{abstract}
Objective: To determine whether intraocular treatment with vascular endothelial growth factor (VEGF) inhibitors change systemic endothelial function (EF) in patients with neovascular age-related macular degeneration (AMD). Methods: In this prospective, randomized, 2-center, double-masked controlled interventional trial, patients with neovascular and dry AMD were enrolled. Eligible neovascular AMD patients received 2 intravitreal loading doses of either ranibizumab 0.5 mg or bevacizumab 1.25 mg at 4-week intervals and were subsequently followed every 4 weeks and treated according to a pro re nata regime for up to 1 year. Patients with dry
\end{abstract}

\section{KARGER}

(C) 2017 S. Karger AG, Basel

E-Mail karger@karger.com

www.karger.com/oph
AMD served as controls. The primary endpoint was the change in EF assessed by flow-mediated dilatation (FMD) after 2 months of treatment with VEGF inhibitors in patients with AMD compared to patients with dry AMD. FMD was assessed with B-mode high-resolution ultrasonography of the left brachial artery. Results: 24 patients with neovascular AMD and 26 patients with dry ADM were included in the trial. Treatment with VEGF inhibitors did not significantly change FMD (from $4.7 \pm 2.4$ to $3.9 \pm 1.9 \%$ after 8 weeks, $p=$ 0.07 , and to $5.1 \pm 2.0 \%$ after 1 year; $p=0.93$ vs. baseline, respectively). Conclusions: EF did not significantly differ between patients with neovascular AMD treated with intravitreal VEGF inhibition and patients with dry AMD.

(c) 2017 S. Karger AG, Basel

ClinicalTrials.gov Identifier: NCT00727753.

Frank Enseleit and Stephan Michels contributed equally to this work.

Frank Enseleit, MD, FESC

University Heart Center

Rämistrasse 100

CH-8091 Zurich (Switzerland)

E-Mail frank.enseleit@usz.ch 


\section{Introduction}

Over the last decade anti-vascular endothelial growth factor (VEGF) therapy has become the gold standard in the treatment of neovascular age-related macular degeneration (AMD). Recently, multiple controlled clinical trials comparing the 2 most commonly used VEGF inhibitors bevacizumab and ranibizumab have shown similar functional results in patients with neovascular AMD [14]. However, systemic safety of intravitreal anti-VEGF therapy remains controversial. None of the prospective clinical trials were designed to evaluate rare systemic events, and even meta-analyses have insufficient power to conclusively exclude anti-VEGF therapy-induced systemic adverse effects [5]. Importantly, none of these trials specifically addressed cardiovascular safety, which is of particular concern, as patients with AMD are predominantly elderly and present with a number of cardiovascular risk factors and/or established cardio- and cerebrovascular disease [6-9].

Intraocular VEGF antagonism constitutes a breakthrough in neovascular AMD management by reducing AMD-related loss of visual acuity [10]. However, an interdisciplinary discussion brings various aspects of VEGF inhibition into focus. In view of the well-established cardioprotective effects of VEGF and its downstream denominator nitric oxide (NO), the beneficial local effects of VEGF inhibition on choroidal neovascularization (CNV) may come at the cost of systemic side effects related to VEGF inhibition such as increased thromboembolic events [11]. Several clinical studies have indicated that serum and plasma VEGF levels are reduced following intravitreal anti-VEGF therapy $[12,13]$. This reduction might be dependent on the drug and treatment strategy. It is, however, unclear to which extent the reduction in unbound VEGF has a relevant effect on vascular endothelial function (EF). One of the most established and sensitive markers of $\mathrm{EF}$ in patients, an independent predictor of cardiovascular events, is the measurement of flow-mediated dilatation (FMD) [14]. As impaired bioavailability of NO within the vascular wall is considered a hallmark of endothelial dysfunction, and endothelial NO release is the downstream denominator of VEGF, there is concern that anti-VEGF therapy decreases NO and thus impairs EF $[11,15,16]$.

Thus, this prospective, 2-center, randomized, doublemasked, controlled, interventional trial was designed to investigate both the local effects of intravitreal VEGF antagonism on $\mathrm{CNV}$ and macular edema, as assessed by fluorescein angiography (FA), optical coherence tomog- raphy (OCT), and best corrected visual acuity (BCVA), and, at the same time, systemic effects on EF, vascular compliance, and 24-h blood pressure in patients with neovascular (wet) AMD, receiving anti-VEGF therapy compared to patients with dry AMD without anti-VEGF therapy.

\section{Methods}

\section{Study Population}

In this prospective, 2-center, randomized, double-masked, controlled, interventional trial, patients with wet (neovascular) AMD (documented by OCT and FA) suitable for intravitreal antiVEGF therapy were recruited at the Department of Ophthalmology, University Hospital Zurich, and the Department of Ophthalmology, Stadtspital Triemli Zurich (both in Switzerland). Patients were on stable medication for general conditions for $\geq 1$ month and were $>50$ years of age, and gave written informed consent. Inclusion criteria for the control group were the same as for the antiVEGF treatment group except for the diagnosis of dry AMD, which was defined as at least category 2 according to the Age-Related-Eye-Disease-Study (AREDS) [17] in both eyes and no evidence of neovascularization in either eye.

Exclusion criteria were acute myocardial infarction, unstable angina, stroke, or a coronary intervention/revascularization procedure $\leq 3$ months prior to study entry, uncontrolled symptomatic congestive heart failure (New York Heart Association functional class $>$ II) $\leq 4$ weeks prior to study entry, renal failure (creatinine clearance using the MDRD formula [18] $<50 \mathrm{~mL} / \mathrm{min}$ ), ventricular tachyarrhythmia, poorly controlled blood pressure despite adequate therapy $(\geq 160 / 100 \mathrm{~mm} \mathrm{Hg})$, symptomatic hypotension, chronic use of long-acting nitrates, smoking ( $>5$ cigarettes/ day), diabetes mellitus, dyslipidemia (LDL cholesterol $>4.5$ $\mathrm{mmol} / \mathrm{L}$ ), liver disease (ALT or AST $>3 \times \mathrm{ULN}$ ), alcohol or illicit substance abuse, known hypersensitivity to the active study drugs or to any of the excipients, active or suspected ocular or periocular infections, active severe intraocular inflammation, malignancy (unless healed or remission $>5$ years), systemic inflammatory diseases (e.g., rheumatoid arthritis or Crohn disease) and the participation in another study within 1 month prior to study entry.

\section{Study Design and Protocol}

According to the study protocol, 50 patients with neovascular AMD who were scheduled for treatment (2 initial injections at 4-week intervals) with ranibizumab (Novartis Pharma Schweiz AG, Rotkreuz, Switzerland) or bevacizumab (Roche Pharma Schweiz AG, Reinach, Switzerland) were scheduled to be included in the study. Patients were seen every 4 weeks, and retreatment was conducted - following the two loading doses - according to the pro re nata (PRN) regimen of the 2nd year in the PrONTO study [19]. Moreover, 25 control subjects with dry AMD were scheduled to be recruited at the same centers. This design was chosen because placebo injections in patients with wet AMD were considered unethical due to the proven marked improvement in visual acuity following intravitreal VEGF antagonism. The primary endpoint was the impact of ranibizumab or bevacizumab on endotheliumdependent and -independent vasodilatation after 8 weeks of treat-
206

Ophthalmologica 2017;238:205-216 DOI: $10.1159 / 000478665$
Enseleit et al. 
Fig. 1. a Treatment schedule. 24-h BP, 24-h ambulatory blood pressure monitoring; BS, blood sample; VC, vascular compliance; CAP, central aortic pressure; $\mathrm{EF}$, endothelial function assessed by flow-mediated dilatation; FA, fluorescein angiography; OCT, optical coherence tomography; VA, visual acuity. b CONSORT flow diagram of all patients included in the SAVEAMD Trial.

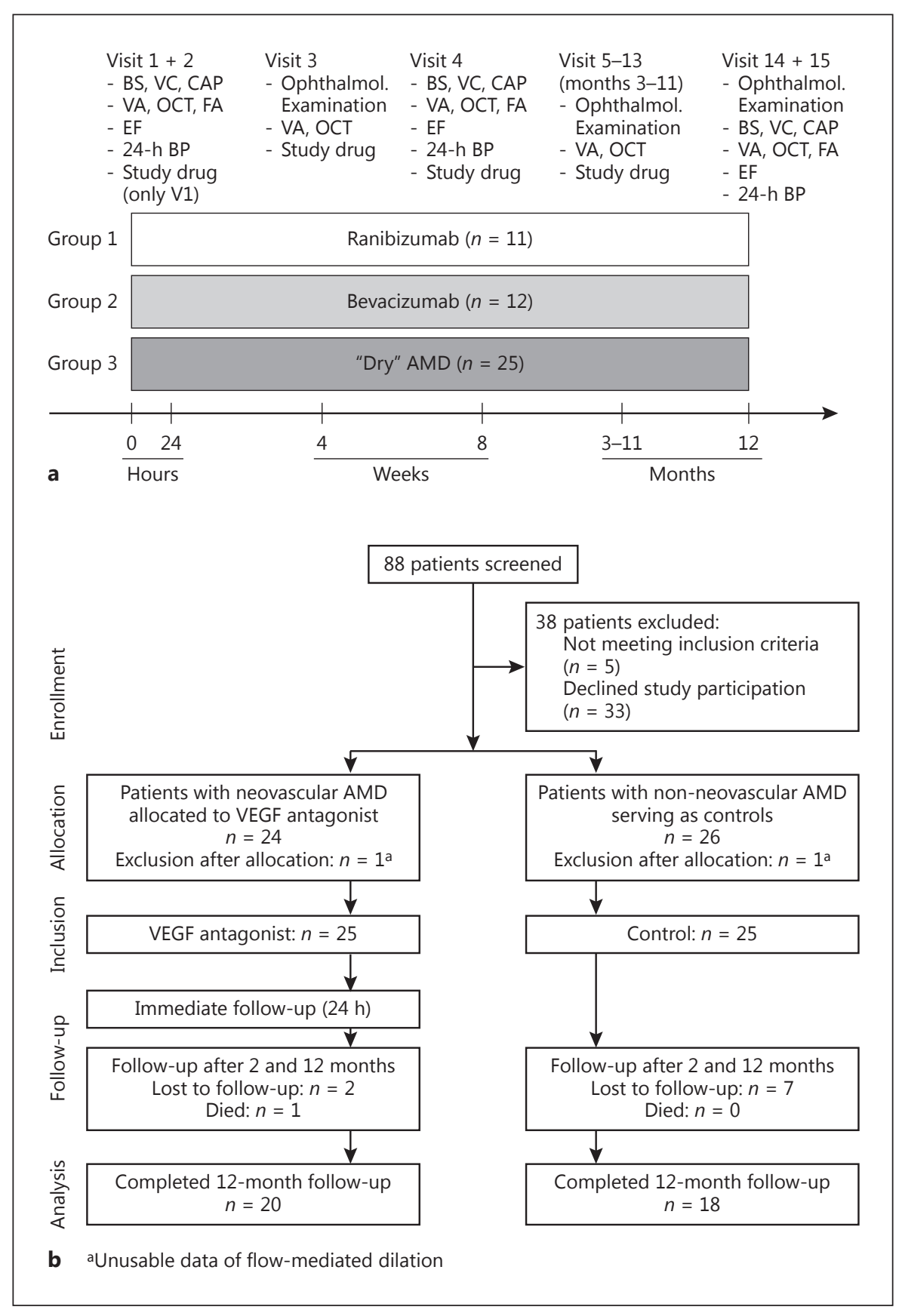

ment in patients with wet AMD compared to a control group of untreated patients with dry AMD. Prespecified secondary endpoints were changes in vascular compliance, mean BCVA and $\mathrm{CNV}$ activity (as determined by central retinal thickness using OCT), and changes in systemic inflammatory markers, surrogates for oxidative stress, and mean systolic and diastolic 24-h blood pressure. Prespecified safety endpoints were incidence of any systemic and ocular adverse events, including death, thromboembolic events, and changes in safety laboratory assessments and vital signs versus baseline. On visit 1 (day 0 ), after obtaining informed consent, medical history was taken, physical examinations, e.g., FA, OCT, BCVA, complete ophthalmic examination, vascular compliance, EF, and 24-h blood pressure, were performed, and blood samples were drawn for systemic analyses. After completing the examination, the study drug $(0.5 \mathrm{mg}$ ranibizumab or $1.25 \mathrm{mg}$ bevacizumab) was administered according to randomization (visit 1, day 0); $24 \mathrm{~h}$ after the study drug administration, a second assessment of EF and vascular compliance was performed, and blood samples for systemic analyses were again drawn to assess immediate effects (visit 2, day 1). After 4 weeks, the study drug was re- 
administered (visit 3, day $28 \pm 2$ ). On visit 4 (day $56 \pm 2$ ) and visit 14 (week $52 \pm 1$ ), vascular compliance, EF, and 24-h blood pressure monitoring were performed, and blood was sampled for systemic analyses (Fig. 1a). On visits 4-13 ophthalmological examinations were performed, and ranibizumab/bevacizumab was administered depending on the results of the aforementioned examinations using strict PRN retreatment criteria according to the 2 nd year of the PrONTO study [19].

Patients were advised not to take any drugs (regular medication) on the day of cardiovascular examination, especially no $\beta$-blocker, calcium antagonist, or angiotensin-converting enzyme inhibitor. All examinations and measurements were performed in the morning. The medical therapy was not changed throughout the study. All patients with wet AMD receiving intravitreal antiVEGF therapy received routine 4-weekly ophthalmological follow-up including BCVA, complete ophthalmological examination, and OCT. All patients with dry AMD had a routine ophthalmological follow-up at baseline and on weeks 8 and 52 including assessment of visual acuity, complete ophthalmic examination, and OCT. The trial was conducted in compliance with the proto$\mathrm{col}$, guidelines for good clinical practice, and the applicable regulatory requirements. The local ethics committee (EK-No. 770) and Swissmedic approved the study. All participants gave written informed consent, and the trial was registered at ClinicalTrials.gov (Identifier: NCT00727753).

\section{Endothelium-Dependent and-Independent Vasodilatation}

FMD was performed according to the current guidelines [20] and as previously described [21]. Briefly, a B-mode high-resolution ultrasound scan of the left brachial artery was obtained by highly trained and experienced sonographers in a longitudinal section between 2 and $10 \mathrm{~cm}$ above the elbow, using a high-resolution $10-\mathrm{MHz}$ linear array transducer and a high-resolution ultrasound system (Siemens X300; Siemens Switzerland AG, Zurich, Switzerland). The analogue video signal was acquired with a video processing system that computed the artery diameter in real-time (FMD Studio [22], a system for real-time measurement; Institute of Clinical Physiology, Pisa, Italy). The high reproducibility of the method has been demonstrated recently [23, 24]. Baseline vessel size was considered as the mean of the measures obtained during the 1 st min. FMD was calculated as the maximal percent increase in diameter above baseline. A reduction in FMD is regarded as EF worsening. Endothelium-independent dilatation was measured after sublingual glycerol trinitrate (GTN; $0.4 \mathrm{mg}$, Nitrolingual spray; Pohl-Boskamp, Hohenlockstedt, Germany) application by recording arterial diameter continuously for at least $6 \mathrm{~min}$. The response to GTN was calculated as the maximum percent increase in vessel size above baseline.

Special Laboratory Analyses

Oxidative Stress Marker

8-Epi-PGF $2 \alpha\left(15-\mathrm{F}_{2 \mathrm{t}}\right.$-isoprostane) was measured in the plasma with an 8-isoprostane enzyme immunoassay (8-Isoprostane Express EIA Kit; Cayman Chemicals, Ann Arbor, MI, USA; intraassay coefficient of variation, CV, 7.2\%, interassay CV 15.5\%).

Prostaglandins and Thromboxane

Prostaglandin $\mathrm{E}_{2}\left(\mathrm{PGE}_{2}\right)$ was measured in plasma using the $\mathrm{PGE}_{2}$ EIA Kit - monoclonal (Cayman Chemicals; intra-assay CV $3.7 \%$, interassay CV $11.6 \%)$. Thromboxane $\mathrm{B}_{2}\left(\mathrm{TBXB}_{2}\right)$ was deter- mined in plasma using the $\mathrm{TBXB}_{2}$ EIA Kit (Cayman Chemicals; intra-assay CV 19.9\%, interassay CV 24.3\%).

Vascular Endothelial Growth Factor

VEGF concentration in plasma samples was determined using the Quantikine Human VEGF Immunoassay, a sandwich ELISA system provided by R \& D Systems (Abingdon, UK). ELISA was performed precisely according to the provider's recommendations. The minimal detectable dose is typically $<9.0 \mathrm{pg} / \mathrm{mL}$ according to the manufacturer.

\section{Ambulatory Blood Pressure Measurement}

Ambulatory blood pressure was assessed over $24 \mathrm{~h}$ using the Tracker NIBP 2 (Delmar ${ }^{\circledR}$; Del Mar Reynolds Medical, Hertford, UK) before and after the treatment phase according to current guidelines [25]. Patients were asked to keep their arm calm while the cuff was inflating and to avoid excessive physical activity during monitoring. The monitors were programmed to take readings every 15 min during daytime and every 30 min during nighttime.

\section{Vascular Compliance}

Arterial stiffness was determined by assessment of pulse wave velocity (PWV) and augmentation index (AIX) with the SphygmoCor applanation tonometer system (AtCor Medical Inc, Itasca, IL, USA) according to established protocols $[26,27]$. PWV was measured between the carotid and femoral artery according to the recent guidelines for assessment of arterial compliance [28]. Patients rest in the supine position for $15 \mathrm{~min}$; measurements were taken immediately after recording of brachial blood pressure. AIX was assessed at the level of the brachial artery by obtaining 10 highquality PWV measurements with automatic calculation of AIX using the manufacturer's proprietary software after normalization of heart rate to $75 \mathrm{bpm}$. Carotid-femoral PWV was calculated by dividing the distance to the distal site by the pressure wave transit time. Transit time between arterial sites was determined in relation to the $\mathrm{R}$ wave of the electrocardiogram (ECG). The surface distance from the suprasternal notch to the distal (femoral) recording site was measured, and the pressure wave transit time was calculated using a foot-of-the-wave to foot-of-the-wave method. A single high-fidelity applanation tonometer (Millar, Houston, TX, USA) was used to obtain a proximal and a distal pulse recorded sequentially a short time apart. Then transit time was obtained by subtraction from the delays between ECG and both pulses.

\section{Shear Stress-Dependent Platelet Function}

Shear stress-dependent platelet function was assessed with a cone and platelet analyzer as described previously [21].

\section{Ophthalmological Methods}

Methods used for ophthalmic evaluation included BCVA using the retro-illuminated, standardized charts (Precision vision, La Salle, IL, USA) of the Early Treatment Diabetic Retinopathy Study (ETDRS) at $4 \mathrm{~m}, \mathrm{FA}$ of the retina performed with the Heidelberg Retina Angiograph II (Heidelberg Engineering, Heidelberg, Germany) and the Spectralis spectral domain OCT system (Heidelberg Engineering) for transsectional analysis of the retina. The automated segmentation software of the Spectralis system was used for calculation of the central retinal thickness (CRT). All three evaluations were performed according to standardized protocols established for clinical trials. 
All patients with the neovascular form of AMD obtained intravitreal injections of either ranibizumab (Lucentis ${ }^{\circledR}$; Novartis AG, Basel, Switzerland) or bevacizumab (Avastin ${ }^{\circledR}$; Hoffmann La Roche AG, Basel, Switzerland). Bevacizumab was compounded into sterile, prefilled syringes by the Swissmedic-certified pharmacy at the City Hospital Triemli Zurich using isolators (ENVAIR; Haslingden, Rossendale, UK). All intravitreal injections were performed according to a standardized procedure including preinjection of topical anesthetics and $5 \%$ povidone iodine, as well as the injection of $0.5 \mathrm{mg}$ ranibizumab $(0.05 \mathrm{~mL})$ or $1.25 \mathrm{mg}$ bevacizumab $(0.05 \mathrm{~mL})$ into the vitreous cavity under sterile conditions in a fully equipped operating room including laminar airflow in the operating field. Details of the injection procedure are described in a recent publication [29].

\section{Statistical Analysis}

The treatment effect of the VEGF antagonists ranibizumab or bevacizumab was compared to no treatment (dry AMD). Furthermore, EF differences before and after treatment were analyzed. Power calculation was based upon the results of the study protocol reported by Chenevard et al. [30]. The primary endpoint was defined as difference in FMD between baseline and after 8 weeks of treatment with a VEGF antagonist. Based on previous experience [30], we hypothesized a difference in the (mean) FMD of $1.3 \pm 1.5 \%$ between baseline and 8 weeks. Using an a error level of $0.05,25$ patients per treatment group were needed to reach a statistical power of 0.8. Descriptive data are given as means \pm SD. For statistical analyses, patients receiving ranibizumab or bevacizumab were both analyzed for the primary endpoint as per protocol, and data of both treatment groups were pooled in the group "VEGF antagonist" treatment (no difference in prespecified cardiovascular endpoints between patients receiving bevacizumab and ranibizumab) and compared to dry AMD. Within-group differences of outcome variables (FMD and secondary outcome variables) were examined by the Wilcoxon signed-rank test. Between-group differences were calculated using the Mann-Whitney U test. Calculations were performed using SPSS 20.0 for Mac (SPSS Inc., Chicago, IL, USA).

\section{Results}

\section{Study Population}

Of 88 patients screened (Fig. 1b), 24 patients with wet AMD were randomized to ranibizumab or bevacizumab, and 26 patients with dry AMD were included in the control group. In each of these groups, 1 patient was excluded due to unusable data of the FMD measurements (Fig. 1b). At baseline, patient characteristics and laboratory parameters, with the exception of serum albumin levels, which were lower in patients with dry than wet AMD, did not differ between groups (Tables 1, 2).

Importantly, due to thromboembolic events occurring in 3 patients, the events were reviewed by an independent data safety monitoring board (Chair: Prof. Ferenc Follath, MD). All thromboembolic events ( 1 fatal stroke, 1 pulmonary embolism, and 1 suspected transient ischemic attack) occurred in patients receiving VEGF inhibitors. Al-
Table 1. Patient characteristics and concomitant medication

\begin{tabular}{|c|c|c|c|}
\hline & $\begin{array}{l}\text { Neovascular } \\
\text { AMD treated } \\
\text { with VEGF } \\
\text { inhibitors }\end{array}$ & $\begin{array}{l}\text { Control } \\
\text { (dry AMD) }\end{array}$ & $\begin{array}{l}p \\
\text { value }\end{array}$ \\
\hline Patients, $n$ & 23 & 25 & \\
\hline Females & $12(52 \%)$ & $15(60 \%)$ & \\
\hline Age, years & $76.5 \pm 6.7$ & $74.8 \pm 6.7$ & 0.32 \\
\hline Body weight, kg & $74.2 \pm 12.6$ & $70.1 \pm 15.8$ & 0.30 \\
\hline Heart rate, bpm & $64 \pm 13$ & $64 \pm 9$ & 0.54 \\
\hline \multicolumn{4}{|l|}{ Blood pressure, $\mathrm{mm} \mathrm{Hg}$} \\
\hline Systolic & $130 \pm 12$ & $127 \pm 14$ & 0.18 \\
\hline Diastolic & $74 \pm 7$ & $74 \pm 8$ & 0.69 \\
\hline \multicolumn{4}{|c|}{ Concomitant medication, $n(\%)$} \\
\hline Aspirin & $5(22)$ & $7(28)$ & \\
\hline Clopidogrel & $0(0)$ & $1(4)$ & \\
\hline Vitamin $\mathrm{K}$ antagonist & $1(4)$ & $1(4)$ & \\
\hline Statins & $6(26)$ & $6(24)$ & \\
\hline ACEI/AR & $6(26)$ & $10(40)$ & \\
\hline$\beta$-Blockers & $7(30)$ & $6(24)$ & \\
\hline Diuretics & $4(17)$ & $8(32)$ & \\
\hline Calcium antagonists & $2(9)$ & $4(16)$ & \\
\hline NSAIDs & $6(26.1)$ & $1(4)$ & \\
\hline
\end{tabular}

ACEI, angiotensin-converting enzyme inhibitor; ARB, angiotensin receptor blocker; NSAIDs, non-steroidal anti-inflammatory drugs.

though the data safety monitoring board could neither prove nor exclude a causal relationship with the respective study drugs, the investigators independently took the decision to stop the study. Ultimately, a total of 38 patients completed the 12-month follow-up: 20 patients with wet and 18 patients with dry AMD.

\section{Effects of VEGF Inhibitors on Cardiovascular Parameters}

Treatment with VEGF inhibitors did not significantly change FMD (from $4.7 \pm 2.4$ to $3.9 \pm 1.9 \%, p=0.07$, baseline vs. 8 weeks, and to $5.1 \pm 2.0 \% ; p=0.93$ baseline vs. after 1 year; Fig. 2a). FMD was lower in the control group $(6 \pm 3.9$ vs. $5.1 \pm 2.2 \% ; p=0.03)$ after 8 weeks as well as after 1 year $(4.6 \pm 2.8 \%, p=0.01$ vs. baseline; Fig. $2 a)$. Endothelium-independent dilatation induced by GTN remained unchanged before and after treatment with VEGF inhibitors (baseline vs. 2 months: $p=0.44$, baseline vs. 12 months: $p=0.52$ ), as well as in the control group (baseline vs. 2 months: $p=0.81$, baseline vs. 12 months: $p=0.41$ ). No differences in FMD were found between patients receiving ranibizumab and patients receiving bevacizumab (ranibizumab vs. bevacizumab: $p=0.94$ after 2 months 
Table 2. Laboratory parameters at baseline in both treatment groups

\begin{tabular}{|c|c|c|c|}
\hline & $\begin{array}{l}\text { VEGF } \\
\text { antagonist }\end{array}$ & $\begin{array}{l}\text { Control } \\
\text { (dry AMD) }\end{array}$ & $\begin{array}{l}p \\
\text { value }\end{array}$ \\
\hline Patients, $n$ & 23 & 25 & \\
\hline Hemoglobin, g/dL & $14.6 \pm 1.4$ & $14.4 \pm 1.3$ & 0.64 \\
\hline Hematocrit. \% & $43 \pm 3.9$ & $42.7 \pm 3.7$ & 0.83 \\
\hline Erythrocytes, $\times 10^{6} / \mu \mathrm{L}$ & $4.8 \pm 0.5$ & $4.8 \pm 0.5$ & 0.64 \\
\hline $\mathrm{MCV}, \mathrm{fL}$ & $89.1 \pm 3.5$ & $89.3 \pm 3.9$ & 0.93 \\
\hline $\mathrm{MCH}, \mathrm{pg}$ & $30.3 \pm 1.4$ & $30.1 \pm 1.8$ & 0.55 \\
\hline $\mathrm{MCHC}, \mathrm{g} / \mathrm{dL}$ & $34 \pm 1$ & $33.7 \pm 1.4$ & 0.64 \\
\hline Platelets, $\times 10^{3} / \mu \mathrm{L}$ & $267 \pm 46$ & $258 \pm 71$ & 0.4 \\
\hline Leukocytes, $\times 10^{3} / \mu \mathrm{L}$ & $6.5 \pm 1.6$ & $6.1 \pm 1.8$ & 0.34 \\
\hline Lymphocytes, $\times 10^{3} / \mu \mathrm{L}$ & $1.6 \pm 0.5$ & $1.5 \pm 0.5$ & 0.32 \\
\hline Sodium, $\mathrm{mmol} / \mathrm{L}$ & $141 \pm 3$ & $141 \pm 3$ & 0.99 \\
\hline Potassium, mmol/L & $3.8 \pm 0.4$ & $3.9 \pm 0.3$ & 0.51 \\
\hline Magnesium, mmol/L & $0.9 \pm 0.1$ & $0.9 \pm 0.1$ & 0.99 \\
\hline Phosphate, $\mathrm{mmol} / \mathrm{L}$ & $0.9 \pm 0.1$ & $0.9 \pm 0.1$ & 0.99 \\
\hline Creatinine, $\mu \mathrm{mol} / \mathrm{L}$ & $83.3 \pm 15.7$ & $81.3 \pm 16.7$ & 0.51 \\
\hline Albumin, $\mathrm{g} / \mathrm{L}$ & $44.4 \pm 2.2$ & $42.5 \pm 3$ & 0.01 \\
\hline $\mathrm{AST}, \mathrm{U} / \mathrm{L}$ & $27.4 \pm 5.3$ & $26.6 \pm 5.3$ & 0.56 \\
\hline $\mathrm{ALT}, \mathrm{U} / \mathrm{L}$ & $23.1 \pm 8.6$ & $20.7 \pm 8.3$ & 0.2 \\
\hline Alkaline phosphatase, U/L & $69.2 \pm 14$ & $62.7 \pm 11.1$ & 0.09 \\
\hline C-reactive protein, $\mathrm{mg} / \mathrm{L}$ & $4.6 \pm 5.5$ & $5.2 \pm 12.1$ & 0.84 \\
\hline Glucose, $\mathrm{mmol} / \mathrm{L}$ & $5.6 \pm 0.5$ & $5.4 \pm 0.6$ & 0.1 \\
\hline Total cholesterol, $\mathrm{mmol} / \mathrm{L}$ & $5.4 \pm 0.9$ & $5.8 \pm 0.7$ & 0.28 \\
\hline HDL cholesterol, mmol/L & $1.5 \pm 0.5$ & $1.8 \pm 0.4$ & 0.34 \\
\hline LDL cholesterol, mmol/L & $3.3 \pm 0.8$ & $3.4 \pm 0.7$ & 0.61 \\
\hline Triglycerides, $\mathrm{mmol} / \mathrm{L}$ & $1.3 \pm 0.4$ & $1.3 \pm 0.5$ & 0.74 \\
\hline Thromboxane $\mathrm{B}_{2}, \mathrm{pg} / \mathrm{mL}$ & $29.3 \pm 4.4$ & $27.8 \pm 5.3$ & 0.52 \\
\hline Prostaglandin $\mathrm{E}_{2}, \mathrm{pg} / \mathrm{mL}$ & $20.8 \pm 10.1$ & $24.2 \pm 6$ & 0.3 \\
\hline $15-\mathrm{F}_{2 \mathrm{t}}$-isoprostane, $\mathrm{pg} / \mathrm{mL}$ & $73.4 \pm 39.7$ & $78.4 \pm 28.7$ & 0.25 \\
\hline VEGF, pg/mL & $76.6 \pm 57.1$ & $\mathrm{n} / \mathrm{a}$ & $\mathrm{n} / \mathrm{a}$ \\
\hline
\end{tabular}

Means $\pm \mathrm{SD}$. MCV, mean corpuscular volume; $\mathrm{MCH}$, mean corpuscular hemoglobin; MCHC, mean corpuscular hemoglobin concentration; AST, aspartate aminotransferase; ALT, alanine aminotransferase; HDL, high-density lipoprotein; LDL, lowdensity lipoprotein; VEGF, vascular endothelial growth factor.

and $p=0.53$ after 12 months). Due to the neutral primary endpoint, no further adjustment by center was performed. At baseline, there was no difference in heart rate, blood pressure, and PWV between patients treated with VEGF inhibitors and the control group (Table 3). During the course of the study, diastolic ambulatory blood pressure dropped from $74 \pm 7 \mathrm{~mm} \mathrm{Hg}$ at baseline to $72 \pm 6 \mathrm{~mm} \mathrm{Hg}$ after 12 months $(p=0.03)$ and AIX increased from $30.4 \pm$ 7.2 at baseline to $36.5 \pm 9.3$ after 12 months $(p=0.02)$ in the patients treated with VEGF inhibitors only (Fig. 2b; Table 3). Endothelium-dependent or -independent vascular function, as well as PWV and AIX, did not change $24 \mathrm{~h}$ after the first injection of VEGF antagonists (Table 4).

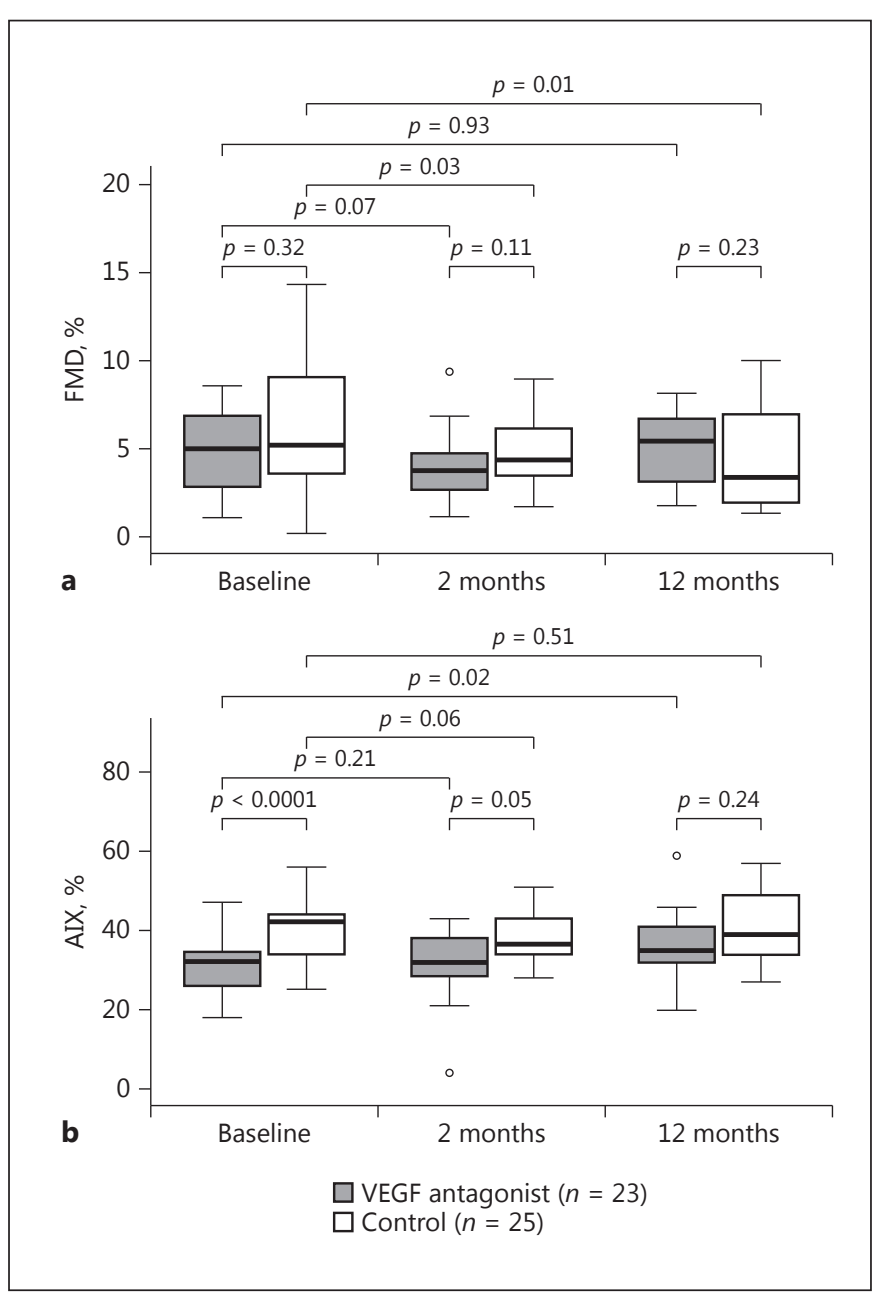

Fig. 2. a Endothelium-dependent vasodilatation in patients with anti-VEGF treatment versus control group. FMD, flow-mediated dilatation. The VEGF antagonist group comprised 23 patients (the 12 -month follow-up was completed by 20 patients; a thromboembolic event occurred in 3 of these patients) and the control group (AMD) comprised 25 patients (the 12-month follow up was completed by 18 patients). b Augmentation index (AIX) in patients with anti-VEGF treatment vs. control group. The VEGF antagonist group comprised 23 patients (the 12-month follow-up was completed by 20 patients; a thromboembolic event occurred in 3 of these patients) and the control group (AMD) comprised 25 patients (the 12 -month follow-up was completed by 18 patients).

\section{Effects of VEGF Inhibitors on Ophthalmological}

\section{Parameters}

At the 2- and 12-month follow-ups, the ophthalmological parameters BCVA and CRT were evaluated as secondary outcomes. At baseline, mean BCVA was 59.2 ETDRS letters $\left(20 / 63^{-1}\right)$ in the eyes with neovascular AMD and 69.5 ETDRS letters $\left(20 / 40^{+1}\right)$ in all eyes with dry AMD of the control group. Under treatment with in- 
Table 3. Differences in body weight, heart rate, systolic/diastolic ambulatory blood pressure (BP), pulse wave velocity (PWV), and augmentation index (AIX) between patients with neovascular age-related macular degeneration (AMD) receiving a VEGF antagonist versus patients with non-neovascular AMD (controls)

\begin{tabular}{|c|c|c|c|c|c|c|c|c|c|c|}
\hline & \multicolumn{3}{|c|}{ Anti-VEGF patients $(n=23)$} & \multirow{2}{*}{$\begin{array}{l}p \\
\text { value }^{\mathrm{a}}\end{array}$} & \multirow{2}{*}{$\begin{array}{l}p \\
\text { value }^{\mathrm{b}}\end{array}$} & \multicolumn{3}{|c|}{ Controls $(n=25)$} & \multirow{2}{*}{$\begin{array}{l}p \\
\text { value }^{\mathrm{a}}\end{array}$} & \multirow{2}{*}{$\begin{array}{l}p \\
\text { value }^{b}\end{array}$} \\
\hline & baseline & 2 mo. & $12 \mathrm{mo}$. & & & baseline & $2 \mathrm{mo}$ & 12 mo. & & \\
\hline Heart rate, bpm & $64 \pm 13$ & $62 \pm 11$ & $61 \pm 9$ & 0.69 & 0.1 & $64 \pm 9$ & $64 \pm 7$ & $64 \pm 8$ & 0.67 & 0.5 \\
\hline Systolic BP, mm Hg & $130 \pm 12$ & $128 \pm 10$ & $129 \pm 14$ & 0.29 & 0.78 & $127 \pm 14$ & $122 \pm 12$ & $123 \pm 11$ & 0.08 & 0.6 \\
\hline Diastolic BP, mm Hg & $74 \pm 7$ & $72 \pm 7$ & $72 \pm 6$ & 0.07 & 0.03 & $74 \pm 8$ & $73 \pm 8$ & $72 \pm 8$ & 0.35 & 0.13 \\
\hline $\mathrm{PWV}, \mathrm{ms}^{-1}$ & $9.2 \pm 2.7$ & $9.1 \pm 2.7$ & $8.7 \pm 2.7$ & 0.61 & 0.4 & $8.7 \pm 2.4$ & $8.8 \pm 2.3$ & $8.3 \pm 1.8$ & 0.7 & 0.63 \\
\hline AIX, $\%$ & $30.4 \pm 7.2$ & $31.9 \pm 9$ & $36.5 \pm 9.3$ & 0.21 & 0.02 & $40.3 \pm 8.3$ & $37.8 \pm 6.6$ & $40.1 \pm 9$ & 0.06 & 0.51 \\
\hline
\end{tabular}

In the group treated with VEGF antagonist, 20 patients completed the 12-month follow-up, and in the control group, 18 patients. a Baseline vs. 2 months. ${ }^{\text {b }}$ Baseline vs. 12 months.

Table 4. Differences in flow-mediated dilatation (FMD), glycerol trinitrate-mediated dilatation (GTN), pulse wave velocity (PWV), and augmentation index (AIX) in patients with neovascular age-related macular degeneration receiving a VEGF antagonist (ranibizumab or bevacizumab)

\begin{tabular}{|c|c|c|c|c|c|c|c|c|c|c|c|c|}
\hline & \multicolumn{2}{|l|}{ FMD, \% } & \multirow{2}{*}{$\begin{array}{l}p \\
\text { value }\end{array}$} & \multicolumn{2}{|l|}{ GTN, \% } & \multirow{2}{*}{$\begin{array}{l}p \\
\text { value }\end{array}$} & \multicolumn{2}{|c|}{$\mathrm{PWV}, \mathrm{ms}^{-1}$} & \multirow{2}{*}{$\begin{array}{l}p \\
\text { value }\end{array}$} & \multicolumn{2}{|l|}{ AIX, \% } & \multirow{2}{*}{$\begin{array}{l}p \\
\text { value }\end{array}$} \\
\hline & baseline & $24 \mathrm{~h}$ & & baseline & $24 \mathrm{~h}$ & & baseline & $24 \mathrm{~h}$ & & baseline & $24 \mathrm{~h}$ & \\
\hline \multirow{2}{*}{$\begin{array}{l}\text { Ranibizumab, } \\
n=11 \\
\text { Bevacizumab, } \\
n=12\end{array}$} & $4.7 \pm 3.5$ & $3.5 \pm 2.7$ & 0.14 & $13.8 \pm 4.9$ & $14.2 \pm 7.3$ & 0.68 & $10.5 \pm 3.3$ & $9.7 \pm 3.6$ & 0.18 & $32.3 \pm 6.4$ & $30.2 \pm 9.6$ & 0.34 \\
\hline & $4.5 \pm 1.8$ & $4.8 \pm 1.9$ & 0.31 & $13.3 \pm 3.8$ & $12.1 \pm 4$ & 0.36 & $7.7 \pm 1.7$ & $8.4 \pm 2.1$ & 0.48 & $27.6 \pm 3.2$ & $29.9 \pm 5.9$ & 0.07 \\
\hline
\end{tabular}

Means \pm SD.

travitreal anti-VEGF therapy, the eyes with neovascular AMD improved nonsignificantly by a mean of 2.8 letters $(p=0.34)$ and 4.2 letters $(p=0.12)$ at the 2 - and 12 -month follow-ups. No significant difference was detected between eyes treated with ranibizumab or bevacizumab. The eyes with dry AMD in the control group showed a mild vision improvement of 0.1 and 0.5 ETDRS letters at the 8- and 52-week follow-ups, respectively. Mean CRT measured by OCT decreased significantly in the group treated with intravitreal anti-VEGF therapy from 401.5 $\mu \mathrm{m}$ at baseline to $285.0 \mu \mathrm{m}(p<0.001)$ and $313 \mu \mathrm{m}(p=$ 0.002 ) at 8 and 52 weeks. No significant difference was observed between both drugs. CRT remained unchanged in the eyes with dry AMD in the control group. CRT was $295.1 \mu \mathrm{m}$ at baseline, $291.9 \mu \mathrm{m}$ at 8 weeks, and $285.4 \mu \mathrm{m}$ at 52 weeks. A mean of 7.5 intravitreal anti-VEGF injections was performed during follow-up. None of the treated eyes had a serious ocular adverse event (e.g., endophthalmitis, retinal detachment, and lens damage).

\section{Effects of VEGF Inhibitors on Special Laboratory Parameters}

VEGF plasma levels were measured in the VEGF inhibitor group only. VEGF plasma levels did not change significantly from $76.6 \pm 57.1 \mathrm{pg} / \mathrm{mL}$ at baseline to $60.4 \pm 31.9 \mathrm{pg} / \mathrm{mL}$ after $24 \mathrm{~h}$ ( $p=0.22$ vs. baseline $)$ and to $80.8 \pm 78.3 \mathrm{pg} / \mathrm{mL}$ after 8 weeks ( $p=0.68$ vs. baseline) during 4-weekly treatment with VEGF inhibitors. All 3 patients with thromboembolic events obtained antiVEGF treatment. At baseline, no difference was detected between the study groups regarding $\mathrm{TBXB}_{2}, \mathrm{PGE}_{2}$, and 15- $\mathrm{F}_{2 \mathrm{t}}$-isoprostane (Table 2). While levels of $\mathrm{PGE}_{2}$ and $15-\mathrm{F}_{2 \mathrm{t}}$-isoprostane did not change throughout the study period (Fig. 3a, c), $\mathrm{TBXB}_{2}$ was significantly reduced after 8 weeks in the control group compared to the VEGF inhibitor group ( $p=0.04$; Fig. $3 b$ ). Platelet adhesion as well as platelet size did not change in either group over time (Fig. 3d, e). 


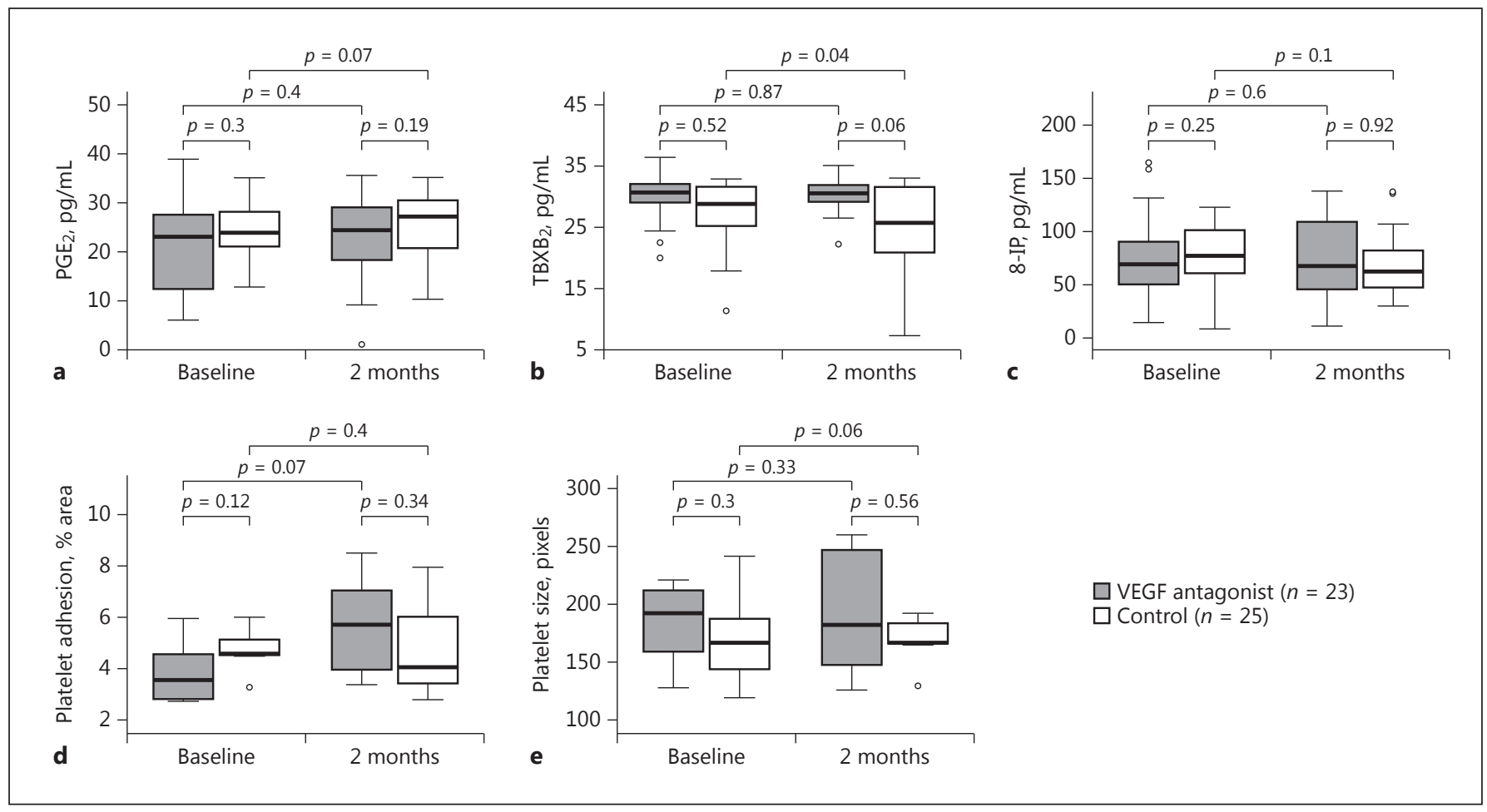

Fig. 3. Plasma levels of prostaglandin $\mathrm{E}_{2}\left(\mathrm{PGE}_{2} ; \mathbf{a}\right)$, thromboxane $\mathrm{B}_{2}\left(\mathrm{TBXB}_{2} ; \mathbf{b}\right), 15-\mathrm{F}_{2 \mathrm{t}}$-isoprostane (8-IP; c), platelet adhesion $(\mathbf{d})$, and platelet size $(\mathbf{e})$ at baseline and after treatment with anti-VEGF treatment versus control group.

\section{Discussion}

The SAVE-AMD trial shows for the first time that acute and long-term treatment up to 1 year with the VEGF inhibitors ranibizumab or bevacizumab in patients with neovascular AMD does not impair EF, platelet function, or blood pressure compared to patients with "dry" AMD.

VEGF plays an important role in the promotion of $\mathrm{CNV}$ and vessel leakage that leads to loss of central vision in AMD [31]. Anti-VEGF therapy improves vision and quality of life in a large number of patients suffering from neovascular "wet" AMD [10, 31]. In 2006, 2 phase III clinical trials with ranibizumab showed that monthly intravitreal injections prevented vision loss and improved visual acuity of patients with neovascular AMD [1, 32]. While intravenous bevacizumab was approved by the FDA for patients with metastatic colorectal cancer in February 2004, the intravitreal use of bevacizumab to treat neovascular AMD has become a common off-label use worldwide due to significantly lower costs compared to ranibizumab. Recently, multiple controlled clinical trials comparing bevacizumab and ranibizumab have shown similar functional results in patients with neovascular AMD [6-9].

EF plays a pivotal role in the pathogenesis and clinical course of atherosclerosis and independently predicts adverse cardiovascular events [14]. In this context, any beneficial effects of anti-VEGF therapies in the eye must be weighed against potential systemic adverse effects of these agents. This is particularly important when potent "pan"anti-VEGF therapies, such as ranibizumab and bevacizumab, may exert systemic extra-ocular side effects by preventing potentially cardioprotective systemic effects of VEGF [31]. As the majority of patients with wet AMD is of advanced age and at increased risk of cardiovascular events, the need to assess cardiovascular safety of these potent drugs is warranted. These findings are of great clinical relevance as large-scale clinical trials specifically addressing the cardiovascular safety of these drugs are lacking.

Repeated injections of anti-VEGF medications can cross the blood-retinal barrier, and the agents may enter the systemic circulation, thereby decreasing systemic VEGF serum concentrations [12,13]. First, although the drug is administered by injection through the sclera into 
the vitreous cavity, systemic absorption may induce systemic adverse effects (mean peak serum concentration after intravitreal injection: ranibizumab $1.5 \mathrm{ng} / \mathrm{mL}$, plasma half-life: $12 \mathrm{~h}$; bevacizumab 3,300 $\mathrm{ng} / \mathrm{mL}$, plasma halflife: 21 days) [13]. Second, because anti-VEGF treatment is potentially required for years, chronic VEGF inhibition may cause side effects that are not immediately apparent. Therefore, VEGF antagonists may be a double-edged sword. While key in the pathogenesis of AMD, VEGF plays at the same time a pivotal role in maintaining systemic vascular integrity, particularly under conditions of ischemia and hypoxia. Indeed, VEGF is an essential element required for reperfusion in myocardial infarction [33] as well as in cerebral ischemia [16, 34]. Moreover, intramyocardial injection of the VEGF 121 isoform ameliorates myocardial ischemia and reduces angina in patients with coronary artery disease [35]. Anti-VEGF agents elicit changes both in the normal and pathological microvasculature, with fenestrated vessels in particular exhibiting sensitivity to VEGF withdrawal $[36,37]$. While 2 studies reported decreased VEGF levels following intravitreal injection of bevacizumab or ranibizumab $[38,39]$, we did not find any differences in VEGF levels before and after treatment with VEGF inhibitors.

Previous randomized clinical trials comparing ranibizumab or bevacizumab reported very low cardiovascular event rates, and as none of these trials had been designed to specifically address cardiovascular safety, a vascular risk associated with these drugs could not be excluded [ 1 , $40,41]$. Intriguingly, the recently published IVAN [42] and CATT [43] trials comparing ranibizumab and bevacizumab in $>1,500$ patients with neovascular AMD demonstrated a significantly increased death rate and a trend to more Antiplatelet Trialists' Collaboration [44] (APTC) events in the treatment arms with fewer treatments (PRN treatment). Interestingly, in the IVAN study, a more pronounced reduction in systemic VEGF levels in eyes treated with bevacizumab compared to ranibizumab and an increased systemic VEGF reduction in frequently versus less frequently (PRN) treated patients was shown. While this finding may be explained in part by the longer halflife of bevacizumab compared with the smaller Fab fragment ranibizumab, no correlation between systemic adverse events in the study and reduced systemic VEGF levels were found [45]. The absence of evidence for a worsening in EF in one vascular bed in AMD patients repeatedly treated with anti-VEGF does not exclude that continuous, monthly intravitreal anti-VEGF over prolonged periods of time has no impact on other vascular beds. In addition, only one systemic vascular bed was

SAVE-AMD Trial evaluated in this study and analysis of cerebral vasculature, for example, might still show impaired NO-dependent EF. Moreover, other NO-unrelated mechanisms may underlie increased rates of thromboembolic events following repeated anti-VEGF treatment observed in this study. Importantly, as VEGF also affects platelet function via the NO pathway [46], VEGF antagonism may exert prothrombotic effects, as suggested by the increased rate of such events in the AMD group.

In line with this interpretation, intravenous use of bevacizumab in cancer patients may have serious systemic complications, including an increased risk of thromboembolic events, hypertension, hemorrhage, proteinuria, impaired wound healing, and gastro-intestinal perforation [47]. However, whether these systemic complications are relevant to AMD patients receiving very low doses by intravitreal injection remains to be determined. Early approval studies with ranibizumab (comparing its effects to placebo or photodynamic therapy) were not designed to assess clinically relevant thromboembolic events. As the latter trials established substantial beneficial effects of intraocular anti-VEGF application on CNV and visual acuity, a comparison to placebo became obsolete in all subsequent randomized controlled trials $[7,47,48]$.

Patients with AMD tend to be older and have an increased prevalence of cardiovascular risk factors such as hypertension and diabetes leading to myocardial infarction or stroke $[31,49,50]$. Indeed, the cardio- and cerebrovascular safety of anti-VEGF therapies was further questioned by reports of an increased incidence of cerebrovascular events in patients treated with ranibizumab, including more and fatal or nonfatal myocardial infarctions compared to control subjects $[51,52]$. At first sight, these findings are in line with our study, which was terminated because 3 of the 56 patients included in the study experienced thromboembolic events, all of which occurred in patients treated with VEGF inhibitors. However, our study was not powered to evaluate thromboembolic events, and the 3 incidences could be due to chance alone in an aged population. Moreover, the cardiovascular risk profile of patients with dry AMD may differ from patients with wet AMD. Meta-analyses, combining the data from various randomized controlled trials, yielded an overall low thromboembolic event rate [16]. In addition, a recent retrospective cohort analysis of United States Medicare beneficiaries with AMD did not show an increased risk for acute myocardial infraction, stroke, or all-cause mortality comparing study cohorts prior and after the introduction of anti-VEGF agents as standard of care for neovascular AMD in 2006 [53].

Ophthalmologica 2017;238:205-216 DOI: $10.1159 / 000478665$ 
The SAVE-AMD study was stopped due to safety concerns, and, therefore, limited the power of the secondary ophthalmological outcomes. BCVA improved in the group with neovascular AMD treated with either ranibizumab or bevacizumab similar to other large prospective clinical trials comparing both drugs [2, 8, 42]. Although improvement in BCVA was not statistically significant, treatment with VEGF antagonists improved visual acuity and reduced CRT comparably to results shown by large randomized clinical trials [41-43]. It is reassuring that CRT was reduced due to the antivascular leakage effects of both drugs resembling the outcomes of other antiVEGF studies in neovascular AMD $[2,8,42]$. In contrast, the control group consisting of dry AMD eyes demonstrated no relevant functional or anatomic change within a 1-year follow-up.

\section{Conclusions}

SAVE-AMD, the first prospective evaluation of the acute and long-term cardiovascular safety of VEGF inhibitors, did not demonstrate a change in EF, vascular compliance, or platelet function. While the study was not powered to assess morbidity and mortality, 3 serious cardiovascular events, all of which occurred in patients treated with VEGF antagonists, may indicate a potential safety hazard. In this context, further interdisciplinary studies are warranted.

\section{Acknowledgments}

The authors would like to thank Silviya Cantatore, RN; Sarah Eisenstein, RN; Astrid Hirt, RN; Priska Kaiser, RN and Manuela Noe, RN, for expert technical assistance and their contributions to operational management of the study. The aforementioned did not receive any compensation except their regular salary.

\section{Disclosure Statement}

Funded by a Swiss National Science Foundation Grant (32003B_130840), the Swiss Heart Foundation, the Werner H. Spross Foundation for Ophthalmology, the Bandung Foundation, and the Austrian Science Fund - FWF (Erwin Schrödinger Stipendium J3559-B23 to O. Schlager). The funding sources had no influence on the design and conduct of the study; collection, management, analysis, and interpretation of the data; and preparation, review, or approval of the manuscript. The foundation for research of the Department of Ophthalmology at the City Hospital Triemli Zurich has received reimbursement for research, consultancy work, and presentations of Stephan Michels on behalf of Novartis and Bayer. T.F. Lüscher has received educational and research grants from Bayer Health Care, Berlin, Germany, and Pfizer Inc., New York, NY, USA, unrelated to this project. The other authors report no conflict of interest in connection with this paper.

\section{Author Contributions}

All authors involved in the trial accepted full responsibility for the design, conduct, analysis and interpretation of the study.

\section{References}

1 Brown DM, Kaiser PK, Michels M, Soubrane G, Heier JS, Kim RY, Sy JP, Schneider S: Ranibizumab versus verteporfin for neovascular age-related macular degeneration. N Engl J Med 2006;355:1432-1444.

2 Group CR, Martin DF, Maguire MG, Ying GS, Grunwald JE, Fine SL, Jaffe GJ: Ranibizumab and bevacizumab for neovascular agerelated macular degeneration. N Engl J Med 2011;364:1897-1908.

3 Heier JS, Boyer DS, Ciulla TA, Ferrone PJ, Jumper JM, Gentile RC, Kotlovker D, Chung CY, Kim RY: Ranibizumab combined with verteporfin photodynamic therapy in neovascular age-related macular degeneration: year 1 results of the focus study. Arch Ophthalmol 2006;124:1532-1542.

4 Solomon SD, Lindsley K, Vedula SS, Krzystolik MG, Hawkins BS: Anti-vascular endothelial growth factor for neovascular age-related macular degeneration. Cochrane Database Syst Rev 2014;8:CD005139.
5 Moja L, Lucenteforte E, Kwag KH, Bertele V, Campomori A, Chakravarthy U, D'Amico R, Dickersin K, Kodjikian L, Lindsley K, Loke Y, Maguire M, Martin DF, Mugelli A, Muhlbauer B, Puntmann I, Reeves B, Rogers C, Schmucker C, Subramanian ML, Virgili G: Systemic safety of bevacizumab versus ranibizumab for neovascular age-related macular degeneration. Cochrane Database Syst Rev 2014;9:CD011230.

6 Risk factors for neovascular age-related macular degeneration. The eye disease case-control study group. Arch Ophthalmol 1992;110: 1701-1708.

7 Bashshur ZF, Bazarbachi A, Schakal A, Haddad ZA, El Haibi CP, Noureddin BN: Intravitreal bevacizumab for the management of choroidal neovascularization in age-related macular degeneration. Am J Ophthalmol 2006; 142:1-9.
8 Krebs I, Schmetterer L, Boltz A, Told R, Vecsei-Marlovits V, Egger S, Schonherr U, Haas A, Ansari-Shahrezaei S, Binder S, Group MR: A randomised double-masked trial comparing the visual outcome after treatment with ranibizumab or bevacizumab in patients with neovascular age-related macular degeneration. Br J Ophthalmol 2013;97: 266-271.

9 Kodjikian L, Souied EH, Mimoun G, MaugetFaysse M, Behar-Cohen F, Decullier E, Huot L, Aulagner G, Group GS: Ranibizumab versus bevacizumab for neovascular age-related macular degeneration: results from the GEFAL Noninferiority Randomized Trial. Ophthalmology 2013;120:2300-2309.

10 Bloch SB, Larsen M, Munch IC: Incidence of legal blindness from age-related macular degeneration in Denmark: year 2000 to 2010 . Am J Ophthalmol 2012;153:209-213.e2. 
11 Winnik S, Lohmann C, Siciliani G, von Lukowicz T, Kuschnerus K, Kraenkel N, Brokopp CE, Enseleit F, Michels S, Ruschitzka F, Luscher TF, Matter CM: Systemic VEGF inhibition accelerates experimental atherosclerosis and disrupts endothelial homeostasis implications for cardiovascular safety. Int J Cardiol 2013;168:2453-2461.

12 Chakravarthy U, Harding SP, Rogers CA, Downes SM, Lotery AJ, Culliford LA, Reeves BC, IVAN Study Investigators: Alternative treatments to inhibit VEGF in age-related choroidal neovascularisation: 2-year findings of the IVAN randomised controlled trial. Lancet 2013;382:1258-1267.

13 Wong TY, Liew G, Mitchell P: Clinical update: new treatments for age-related macular degeneration. Lancet 2007;370:204-206.

14 Schachinger V, Britten MB, Zeiher AM: Prognostic impact of coronary vasodilator dysfunction on adverse long-term outcome of coronary heart disease. Circulation 2000;101: 1899-1906.

15 Tziros C, Freedman JE: The many antithrombotic actions of nitric oxide. Current Drug Targets 2006; 7:1243-1251.

16 Semeraro F, Morescalchi F, Duse S, Gambicorti E, Romano MR, Costagliola C: Systemic thromboembolic adverse events in patients treated with intravitreal anti-VEGF drugs for neovascular age-related macular degeneration: an overview. Expert Opin Drug Saf 2014; 13:785-802.

17 Davis MD, Gangnon RE, Lee LY, Hubbard LD, Klein BE, Klein R, Ferris FL, Bressler SB, Milton RC, Age-Related Eye Disease Study Group: The Age-Related Eye Disease Study Severity Scale for age-related macular degeneration: AREDS Report No. 17. Arch Ophthalmol 2005;123:1484-1498.

18 Levey AS, Bosch JP, Lewis JB, Greene T, Rogers N, Roth D: A more accurate method to estimate glomerular filtration rate from serum creatinine: a new prediction equation. Modification of diet in renal disease study group. Ann Intern Med 1999;130:461-470.

19 Lalwani GA, Rosenfeld PJ, Fung AE, Dubovy SR, Michels S, Feuer W, Davis JL, Flynn HW Jr, Esquiabro M: A variable-dosing regimen with intravitreal ranibizumab for neovascular age-related macular degeneration: year 2 of the PrONTO study. Am J Ophthalmol 2009; 148:43-58.e1.

20 Deanfield J, Donald A, Ferri C, Giannattasio C, Halcox J, Halligan S, Lerman A, Mancia G, Oliver JJ, Pessina AC, Rizzoni D, Rossi GP, Salvetti A, Schiffrin EL, Taddei S, Webb DJ, Working Group on E, Endothelial Factors of the European Society of H: Endothelial function and dysfunction. Part I: methodological issues for assessment in the different vascular beds: a statement by the Working Group on Endothelin and Endothelial Factors of the European Society of Hypertension. J Hypertens 2005;23:7-17.
21 Sudano I, Flammer AJ, Periat D, Enseleit F, Hermann M, Wolfrum M, Hirt A, Kaiser P, Hurlimann D, Neidhart M, Gay S, Holzmeister J, Nussberger J, Mocharla P, Landmesser U, Haile SR, Corti R, Vanhoutte PM, Luscher TF, Noll G, Ruschitzka F: Acetaminophen increases blood pressure in patients with coronary artery disease. Circulation 2010;122: 1789-1796.

22 Faita F, Masi S, Loukogeorgakis S, Gemignani V, Okorie M, Bianchini E, Charakida M, Demi M, Ghiadoni L, Deanfield JE: Comparison of two automatic methods for the assessment of brachial artery flow-mediated dilation. J Hypertens 2011;29:85-90.

23 Gemignani V, Bianchini E, Faita F, Giannarelli C, Plantinga Y, Ghiadoni L, Demi M: Ultrasound measurement of the brachial artery flow-mediated dilation without ECG gating. Ultrasound Med Biol 2008;34:385-391.

24 Gemignani V, Faita F, Ghiadoni L, Poggianti E, Demi M: A system for real-time measurement of the brachial artery diameter in Bmode ultrasound images. IEEE Trans Med Imaging 2007;26:393-404.

25 Mancia G, De Backer G, Dominiczak A, Cifkova R, Fagard R, Germano G, Grassi G, Heagerty AM, Kjeldsen SE, Laurent S, Narkiewicz K, Ruilope L, Rynkiewicz A, Schmieder RE, Struijker Boudier HA, Zanchetti A, Vahanian A, Camm J, De Caterina R, Dean V, Dickstein K, Filippatos G, Funck-Brentano C, Hellemans I, Kristensen SD, McGregor K, Sechtem U, Silber S, Tendera M, Widimsky P, Zamorano JL, Erdine S, Kiowski W, AgabitiRosei E, Ambrosioni E, Lindholm LH, Manolis A, Nilsson PM, Redon J, Struijker-Boudier HA, Viigimaa M, Adamopoulos S, Bertomeu V, Clement D, Farsang C, Gaita D, Lip G, Mallion JM, Manolis AJ, O'Brien E, Ponikowski P, Ruschitzka F, Tamargo J, van Zwieten P, Waeber B, Williams B; The task force for the Management of Arterial Hypertension of the European Society of Hypertension, The Task Force for the Management of Arterial Hypertension of the European Society of Cardiology: 2007 Guidelines for the Management of Arterial Hypertension: The Task Force for the Management of Arterial Hypertension of the European Society of Hypertension (ESH) and of the European Society of Cardiology (ESC). Eur Heart J 2007;28:1462-1536.

26 Laurent S, Cockcroft J, Van Bortel L, Boutouyrie P, Giannattasio C, Hayoz D, Pannier B, Vlachopoulos C, Wilkinson I, StruijkerBoudier H; European Network for Non-Invasive Investigation of Large Arteries: Expert consensus document on arterial stiffness: methodological issues and clinical applications. Eur Heart J 2006;27:2588-2605.

27 Williams B: Evaluating interventions to reduce central aortic pressure, arterial stiffness and morbidity-mortality. J Hypertens 2012; 30(suppl):S13-S18.
28 Pannier BM, Avolio AP, Hoeks A, Mancia G, Takazawa K: Methods and devices for measuring arterial compliance in humans. Am J Hypertens 2002;15:743-753.

29 Casparis $H$, Wolfensberger TJ, Becker M, Eich G, Graf N, Ambresin A, Mantel I, Michels S: Incidence of presumed endophthalmitis after intravitreal injection performed in the operating room: a retrospective multicenter study. Retina 2014;34:12-17.

30 Chenevard R, Hurlimann D, Bechir M, Enseleit F, Spieker L, Hermann M, Riesen W, Gay S, Gay RE, Neidhart M, Michel B, Luscher TF, Noll G, Ruschitzka F: Selective COX-2 inhibition improves endothelial function in coronary artery disease. Circulation 2003; 107:405-409.

31 Enseleit F, Michels S, Ruschitzka F: Current treatment of wet age-related macular degeneration: determining the cardiovascular risk. Br J Cardiol 2009;16:S3-S8.

32 Rosenfeld PJ, Brown DM, Heier JS, Boyer DS, Kaiser PK, Chung CY, Kim RY: Ranibizumab for neovascular age-related macular degeneration. N Engl J Med 2006;355:1419-1431.

33 Infanger M, Faramarzi S, Grosse J, Kurth E, Ulbrich C, Bauer J, Wehland M, Kreutz R, Kossmehl P, Paul M, Grimm D: Expression of vascular endothelial growth factor and receptor tyrosine kinases in cardiac ischemia/ reperfusion injury. Cardiovasc Pathol 2007; 16:291-299.

34 Zlokovic BV: Remodeling after stroke. Nat Med 2006;12:390-391.

35 Rosengart TK, Lee LY, Patel SR, Sanborn TA, Parikh M, Bergman GW, Hachamovitch R, Szulc M, Kligfield PD, Okin PM, Hahn RT, Devereux RB, Post MR, Hackett NR, Foster T, Grasso TM, Lesser ML, Isom OW, Crystal RG: Angiogenesis gene therapy: phase I assessment of direct intramyocardial administration of an adenovirus vector expressing VEGF121 cDNA to individuals with clinically significant severe coronary artery disease. Circulation 1999;100:468-474.

36 Inai T, Mancuso M, Hashizume H, Baffert F, Haskell A, Baluk P, Hu-Lowe DD, Shalinsky DR, Thurston G, Yancopoulos GD, McDonald DM: Inhibition of vascular endothelial growth factor (VEGF) signaling in cancer causes loss of endothelial fenestrations, regression of tumor vessels, and appearance of basement membrane ghosts. Am J Pathol 2004; 165:35-52.

37 Kamba T, Tam BY, Hashizume H, Haskell A, Sennino B, Mancuso MR, Norberg SM, O'Brien SM, Davis RB, Gowen LC, Anderson KD, Thurston G, Joho S, Springer ML, Kuo CJ, McDonald DM: VEGF-dependent plasticity of fenestrated capillaries in the normal adult microvasculature. Am J Physiol Heart Circ Physiol 2006;290:H560-H576.

38 Bakri SJ, Snyder MR, Reid JM, Pulido JS, Singh RJ: Pharmacokinetics of intravitreal bevacizumab (Avastin). Ophthalmology 2007;114:855-859. 
39 Gaudreault J, Fei D, Rusit J, Suboc P, Shiu V: Preclinical pharmacokinetics of ranibizumab (rhuFabV2) after a single intravitreal administration. Invest Ophthalmol Vis Sci 2005;46: 726-733.

40 Brown DM, Michels M, Kaiser PK, Heier JS, Sy JP, Ianchulev T, Group AS: Ranibizumab versus verteporfin photodynamic therapy for neovascular age-related macular degeneration: two-year results of the ANCHOR study. Ophthalmology 2009;116:57-65.e5.

41 Tufail A, Patel PJ, Egan C, Hykin P, da Cruz L, Gregor Z, Dowler J, Majid MA, Bailey C, Mohamed Q, Johnston R, Bunce C, Xing W, $A B C$ Trial Investigators: Bevacizumab for neovascular age related macular degeneration (ABC Trial): multicentre randomised double masked study. BMJ 2010;340:c2459.

42 IVAN Study Investigators, Chakravarthy U, Harding SP, Rogers CA, Downes SM, Lotery AJ, Wordsworth S, Reeves BC: Ranibizumab versus bevacizumab to treat neovascular agerelated macular degeneration: one-year findings from the IVAN randomized trial. Ophthalmology 2012;119:1399-1411.

43 Comparison of AMD Treatments Trials (CATT): Lucentis - Avastin Trial. Bethesda, National Eye Institute, 2008.
44 Collaborative overview of randomised trials of antiplatelet therapy - I: prevention of death, myocardial infarction, and stroke by prolonged antiplatelet therapy in various categories of patients. Antiplatelet Trialists' Collaboration. BMJ 1994;308:81-106.

45 Chakravarthy U, Rogers CA, Reeves BC, Scott L, Harding SP, Downes SM, Lotery A: Alterations in serum vascular endothelial growth factor after intraocular administration of antiVEGF drugs, is there an association with safety outcomes? ARVO Annual Meeting Abstract. IOVS 2014;55:871.

46 Mellion BT, Ignarro LJ, Myers CB, Ohlstein EH, Ballot BA, Hyman AL, Kadowitz PJ: Inhibition of human platelet aggregation by S-nitrosothiols. Heme-dependent activation of soluble guanylate cyclase and stimulation of cyclic GMP accumulation. Mol Pharmacol 1983;23:653-664.

47 Ferrara N, Hillan KJ, Novotny W: Bevacizumab (Avastin), a humanized anti-VEGF monoclonal antibody for cancer therapy. Biochem Biophys Res Commun 2005;333:328335.
48 Algvere PV, Steen B, Seregard S, Kvanta A: A prospective study on intravitreal bevacizumab (Avastin) for neovascular age-related macular degeneration of different durations. Acta Ophthalmol 2008;86:482-489.

49 Duan Y, Mo J, Klein R, Scott IU, Lin HM Caulfield J, Patel M, Liao D: Age-related macular degeneration is associated with incident myocardial infarction among elderly Americans. Ophthalmology 2007;114:732-737.

50 Wong TY, Klein R, Sun C, Mitchell P, Couper DJ, Lai H, Hubbard LD, Sharrett AR: Agerelated macular degeneration and risk for stroke. Ann Intern Med 2006;145:98-106.

51 Ueta T, Yanagi Y, Tamaki Y, Yamaguchi T: Cerebrovascular accidents in ranibizumab. Ophthalmology 2009;116:362.

52 Kemp A, Preen DB, Morlet N, Clark A, McAllister IL, Briffa T, Sanfilippo FM, Ng JQ, McKnight C, Reynolds W, Gilles MC: Myocardial infarction after intravitreal vascular endothelial growth factor inhibitors: a whole population study. Retina 2013;33:920-927.

53 Yashkin AP, Hahn P, Sloan FA: Introducing anti-vascular endothelial growth factor therapies for AMD did not raise risk of myocardial infarction, stroke, and death. Ophthalmology 2016;123:2225-2231. 